\title{
Shear Wave Ultrasound Elastography to Evaluate the State of Renal Transplant
}

\author{
DOI: $10.17691 / \mathrm{stm} 2017.9 .4 .16$
}

Received June 27, 2017

M.G. Tukhbatullin, MD, PhD, Professor, Head of the Department of Ultrasound Diagnostics

Sh.R. Galeev, MD, PhD, Associate Professor, Department of Urology and Nephrology;

L.I. Garifullina, PhD Student, Department of Ultrasound Diagnostics;

R.H. Galeev, MD, PhD, Professor, Head of the Department of Urology and Nephrology

Kazan State Medical Academy - Branch Campus of Russian Medical Academy

of Continuous Professional Education, 36 Butlerova St., Kazan, 420012,

Russian Federation

The aim of the study was to assess possibilities of shear wave ultrasound elastography in evaluating severity of fibrosis of a renal transplant aged from 1 to 3 years and older.

Materials and Methods. In the period from February 9, 2015 to May 25, 2017 we performed 80 ultrasound scans in 44 patients, whose average age was $34.8 \pm 8.9$ (from 17 to 52 years old). Ultrasound scans were performed on Aixplorer (Super Sonic Imagine S.A., AixenProvence, France) with a convex transducer with frequency range 1-6 MHz. The patients were divided into two groups: group 1 ( $n=12$ ) patients with a stable function of their renal transplant, group $2(n=32)$ - patients with deviations in clinical laboratory values (increased creatinine level in blood serum), with recurrent glomerulonephritis and other complications.

Results. In group $1(n=12$, average age $-36.6 \pm 2.1)$, the average measurements of the transplant were the following: length $120.4 \pm 9.7 \mathrm{~mm}$; width $-48.8 \pm 5.5 \mathrm{~mm}$; parenchyma thickness $-14.8 \pm 2.1 \mathrm{~mm}$. In group $2(\mathrm{n}=32$, average age $-42.9 \pm 2.4)$, the measurements of a transplanted kidney were as follows: length $-116.8 \pm 7.9 \mathrm{~mm}$; width $-49.1 \pm 4.4 \mathrm{~mm}$; parenchyma thickness $15.4 \pm 2.3 \mathrm{~mm}$. The average resistance index in interlobar arteries in group 1 was $0.69 \pm 0.09$; in group 2 it was $0.72 \pm 0.03$ ( $p=0.673$ ). In arcuate arteries the resistance index was $0.62 \pm 0.08$ in group 1 and $0.73 \pm 0.01$ in group 2 . The values of parenchyma stiffness of a renal transplant in shear wave ultrasound elastography in different areas were $26.14 \pm 1.50 \mathrm{kPa}$ in group 1 and $28.75 \pm 0.76 \mathrm{kPa}$ in group 2 $(p=0.0099)$. The level of creatinine in the patients from group 1 was $143.3 \pm 11.9 \mu \mathrm{mol} / \mathrm{L}$ and in group 2 it was $161.8 \pm 9.0 \mu \mathrm{mol} / \mathrm{L}$ ( $p=0.268$ ). The correlation ratio $r$ of the values of creatinine and parenchyma stiffness in group 1 was equal to 0.452 ; in group 2, $r$ was 0.375 which is statistically significant.

Conclusion. On the basis of the results of the statistical processing of the data we determined diagnostic significance of shear wave ultrasound elastography for evaluation of the state of a transplanted kidney in short and long terms of follow-up.

Key words: shear wave ultrasound elastography; Doppler sonography; kidney transplant.

Medical ultrasound plays a significant role in differential diagnostics of surgical and non-surgical complications after kidney transplantation as these complications can be clinically manifested in a similar way. Thus, a transplant dysfunction can result from both an acute rejection and extravasation of urine, while fever and painful transplant swelling can be caused by wound infection or rejection.

The principal algorithm of diagnostics of postoperative complications of transplant function requires first and foremost to exclude urological and vascular causes and then to perform differential diagnostics of other states, for example, rejection and nephrotoxicity [1].

In world practice, ultrasound imaging, which includes greyscale scanning (B-mode), color and spectral Doppler mapping, is considered to be one of the leading methods of instrumental diagnostics and monitoring after kidney transplantation [2].
Currently ultrasound elastography, a method of qualitative and quantitative analysis of elastic properties of tissues, is obtaining higher clinical value. Ultrasound elastography is classified into strain elastography and shear wave elastography depending on the calculation method of Young's elastic modulus [3, 4]. The rate of shear wave propagation is determined by $G$ shear modulus which is directly proportional to Young's modulus E. By measuring the rate of shear wave propagation one can obtain quantitative evaluation of Young's modulus $E$, and therefore, quantitatively characterize tissue stiffness. This is a considerable advantage of shear wave ultrasound elastography (SWUE) in comparison with other methods of elastography $[5,6]$.

Initially, SWUE was used for diagnostics of liver diseases. Along with the technology development, it started being used for diagnostics of breast pathology, prostate cancer, ovary cancer, inflammatory changes,

For contacts: Munir G. Tukhbatullin, e-mail: munir.tuhbatullin@tatar.ru 
liver metastases, metastatic lesion of neck lymphatic nodes, thyroid cancer etc. [7, 8]. SWUE is effective in evaluation of liver fibrosis. In this study we used this method to evaluate severity of fibrosis in kidney transplant parenchyma.

The aim of the study was to assess possibilities of shear wave ultrasound elastography in evaluating severity of fibrosis of a renal transplant aged from 1 to 3 years and older.

Materials and Methods. From February 9, 2015 to May 25, 2017 in the Transplantation Department of the Republican Clinical Hospital of the Ministry of Public Health of the Tatarstan Republic (Kazan) we performed 80 ultrasound scans of kidney transplantation in 44 patients, whose average age was $34.8 \pm 8.9$ (from 17 to 52). The ultrasound diagnostics was performed on Aixplorer (Super Sonic Imagine S.A., Aixen-Provence, France) with a convex transducer with frequency range from $1-6 \mathrm{MHz}$.

The study is compliant with Helsinki Declaration accepted in June 1964 (Helsinki, Finland) and reviewed in October 2000 (Edinburgh, Scotland) and was approved by the Ethical Committee of the Republican Clinical Hospital. Every patient gave a written consent to participate in the study.

Ultrasound diagnostics of kidney transplant was performed with SWUE and standard scanning modes:

1) greyscale scanning: evaluation of the state and topometry of the transplant (sizes of the transplant, thickness of the cortical layer, size of the renal collecting system etc.), evaluation of pararenal area;

2) color Doppler mapping of blood flow rate and energy;

3) spectral Doppler investigation.

An obligatory condition for SWUE of kidney transplant was the absence of compression.

We determined resistance indexes in arcuate and interlobar arteries where in early stages hemodynamic changes in kidney transplant are visible. SWUE was used to evaluate average stiffness of parenchyma in the upper and lower poles, lateral and medial edge of the transplant (up to 10 points per one plane). The functional

Table 1

Distribution of the examined patients depending on the main disease that caused chronic renal failure (abs. value/\%)

\begin{tabular}{lccc}
\hline \multicolumn{1}{c}{ The main disease } & $\begin{array}{c}\text { Group 1 } \\
(\mathrm{n}=12)\end{array}$ & $\begin{array}{c}\text { Group 2 } \\
(\mathrm{n}=32)\end{array}$ & $\begin{array}{c}\text { Total } \\
(\mathrm{n}=44)\end{array}$ \\
\hline Alport's syndrome & $0 / 0.0$ & $1 / 3.1$ & $1 / 2.3$ \\
\hline Polycystosis & $0 / 0.0$ & $3 / 9.4$ & $3 / 6.8$ \\
\hline Diabetes mellitus & $1 / 8.3$ & $5 / 15.6$ & $6 / 13.6$ \\
\hline Urolithiasis & $2 / 16.7$ & $6 / 18.8$ & $8 / 18.2$ \\
\hline Chronic glomerulonephritis & $8 / 66.7$ & $16 / 50.0$ & $24 / 54.5$ \\
\hline Chronic pyelonephritis & $1 / 8.3$ & $1 / 3.1$ & $2 / 4.5$ \\
\hline
\end{tabular}

N o te . $p=0.727$ - between group 1 and group 2 . state of the kidney was assessed by measuring the level of creatinine in blood plasma.

The patients who had transplantations 1-3 years and more before were divided into two groups: group 1 $(n=12)$ : patients with a stable function of their renal transplant, group $2(n=32)$ : patients with deviations in clinical laboratory values (increased creatinine level in blood serum), with recurrent glomerulonephritis and other complications. Distribution of the patients depended on the character of the main disease which caused chronic renal failure is presented in Table 1. The most frequent cause was chronic glomerulonephritis, other kidney diseases occurred more rarely.

Statistic processing of the results was performed with SPSS software (v. 18.0). Normality of quantitative parameters distribution was assessed by KolmogorovSmirnov test. A comparison of average values in the groups was made with Student's test. The data are presented as $M \pm m$, where $M$ is the arithmetic mean, $m$ is standard error of mean. To evaluate the correlation between quantitative parameters we used Pearson correlation coefficient. The quantitative parameters were compared with the criterion $X^{2}$ and the exact Fisher's ratio. The differences were considered statistically relevant at $p<0.05$.

Results. The most frequent cause of transplant dysfunction, revealed after the operation, is chronic transplantation nephropathy [1]. In our study its frequency was $77.3 \%$, other causes of dysfunction were observed more rarely (Table 2).

During the evaluation of a transplant state we defined kidney contour, homogeneity and echogenicity of the parenchyma, the state of the renal sinus, the renal collection system and the renal duct.

During topometry we identified the sizes of kidney transplant. In group 1 ( $n=12$, average age $-36.6 \pm 2.1)$ the average measurements of the transplant were the following: length $-120.4 \pm 9.7 \mathrm{~mm}$; width $-48.8 \pm 5.5 \mathrm{~mm}$; parenchyma thickness $-14.8 \pm 2.1 \mathrm{~mm}$. In group $2(\mathrm{n}=32$, average age $-42.9 \pm 2.4$ ) the sizes of a transplanted kidney were as follows: length $-116.8 \pm 7.9 \mathrm{~mm}$; width 49.1 $\pm 4.4 \mathrm{~mm}$; parenchyma thickness $-15.4 \pm 2.3 \mathrm{~mm}$.

To evaluate the state of pararenal area we searched for free fluid around the transplant which can be observed in case of the formation of hematomas, urinomas and lymphocele.

In color Doppler mapping some interlobar and arcuate arteries with well-explicit systolic and diastolic blood flow during the whole cardiac cycle were clearly visualized. The average resistance index in interlobar arteries in group 1 was $0.69 \pm 0.09$; in group 2 it was $0.72 \pm 0.03$ $(p=0.673)$. In arcuate arteries the resistance index was $0.62 \pm 0.08$ in group 1 and $0.73 \pm 0.01$ in group 2 .

The values of parenchyma stiffness of a renal transplant in shear wave ultrasound elastography in different areas were $26.14 \pm 1.50 \mathrm{kPa}$ in group 1 and $28.75 \pm 0.76 \mathrm{kPa}$ in group $2 \quad(p=0.0099)$. The level of creatinine in the patients from group 1 
Table 2

Distribution of the examined patients depending on the dysfunction of kidney transplant (abs. value/\%)

\begin{tabular}{lccc}
\hline \multicolumn{1}{c}{ Dysfunction of kidney transplant } & Group 1 $(\mathrm{n}=12)$ & Group 2 $(\mathrm{n}=32)$ & Total $(\mathrm{n}=44)$ \\
\hline Episode of kidney transplant rejection & $0 / 0.0$ & $4 / 12.5$ & $4 / 9.1$ \\
\hline Recurrent chronic glomerulonephritis & $2 / 16.7$ & $0 / 0.0$ & $2 / 4.5$ \\
\hline Chronic transplantation nephropathy & $9 / 75.0$ & $25 / 78.1$ & $34 / 77.3$ \\
\hline Recurrent chronic pyelonephritis & $1 / 8.3$ & $3 / 9.4$ & $4 / 9.1$ \\
\hline
\end{tabular}

N o te. $p=0.077$ - between group 1 and group 2 .
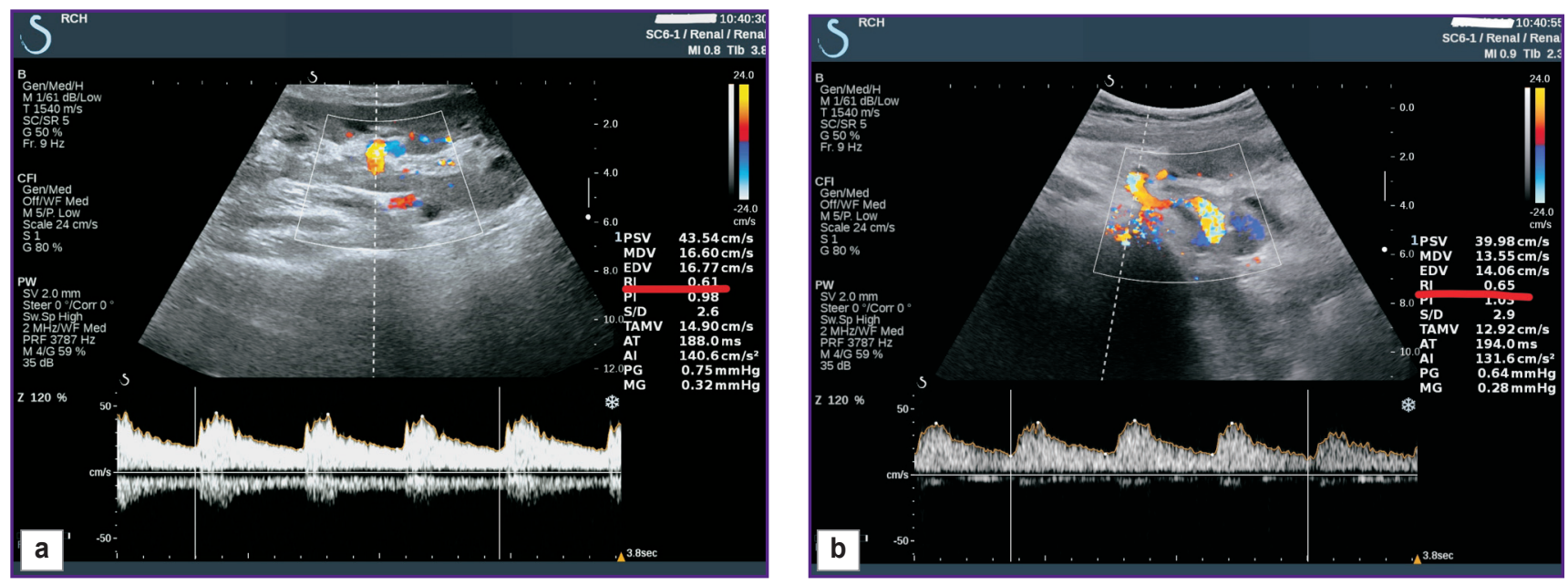

Figure 1. Ultrasound image of the kidney transplant of Patient K. (group 1):

Transplantation performed in 2016; clinical-biological values at admission: creatinine - $156 \mu \mathrm{mol} / \mathrm{L}$, urea - $11.4 \mu \mathrm{mol} / \mathrm{L}$; ultrasound Doppler sonography: (a) in interlobar arteries, resistance index -0.61 ; (b) in interlobar arteries, resistance index -0.65
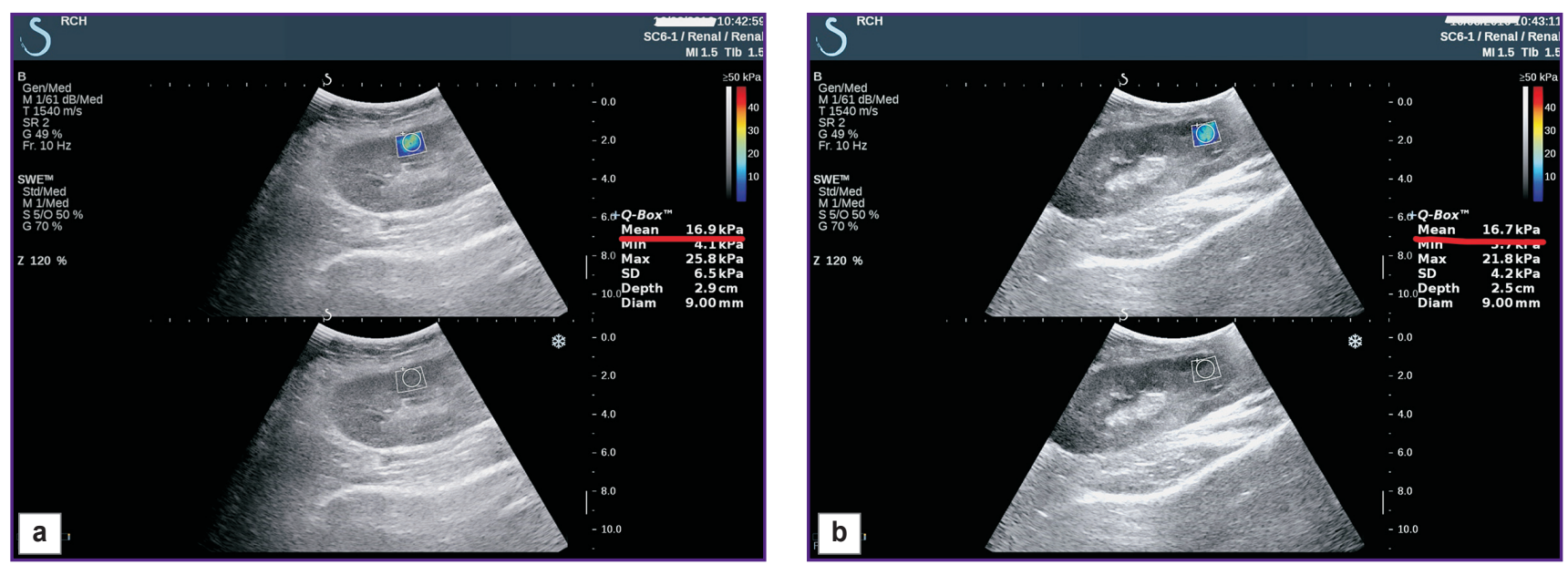

Figure 2. Shear wave ultrasound elastography of Patient K. (group 1):

(a) parenchyma stiffness in the middle third of the kidney transplant is $16.9 \mathrm{kPa}$ (top — the mode of shear wave ultrasound elastography, bottom - greyscale mode); (b) parenchyma stiffness in the upper third of the kidney transplant is $16.7 \mathrm{kPa}$ (top the mode of shear wave ultrasound elastography, bottom - greyscale mode)

was $143.3 \pm 11.9 \mu \mathrm{mol} / \mathrm{L}$ and in group 2 it was $161.8 \pm 9.0 \mu \mathrm{mol} / \mathrm{L} \quad(p=0.268)$. The correlation ratio of the values of creatinine and parenchyma stiffness $r$ in group 1 was equal to 0.452 ; in group $2, r$ was 0.375 which is statistically significant.

Figures 1 and 2 represent the results of evaluation 

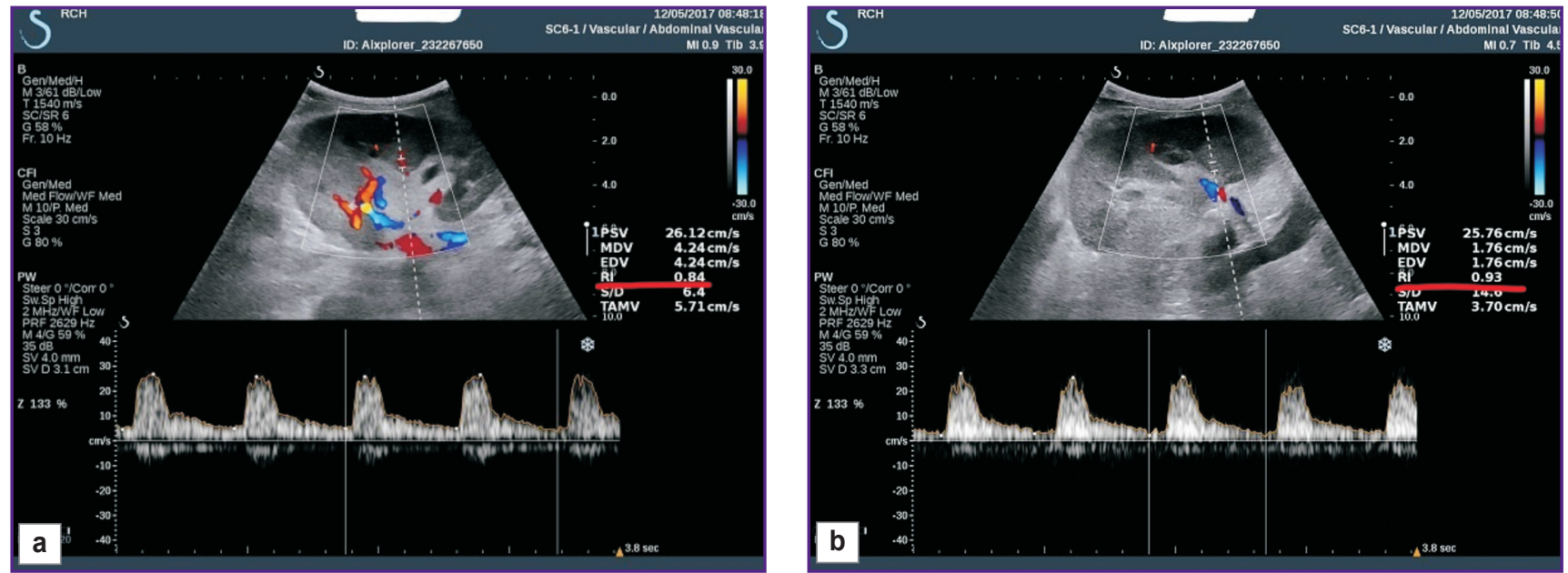

Figure 3. Ultrasound image of kidney transplant of Patient H. (group 2):

Transplantation performed in 2012; diagnosis: "transplantation nephropathy with the loss of function, recurrent chronic glomerulonephritis"; clinical-biochemical values at admission: creatinine $-1131.0 \mu \mathrm{mol} / \mathrm{L}$, urea $-14.4 \mu \mathrm{mol} / \mathrm{L}$; ultrasound Doppler sonography: (a) in interlobar arteries, resistance index -0.84 ; (b) in arcuate arteries, resistance index -0.93
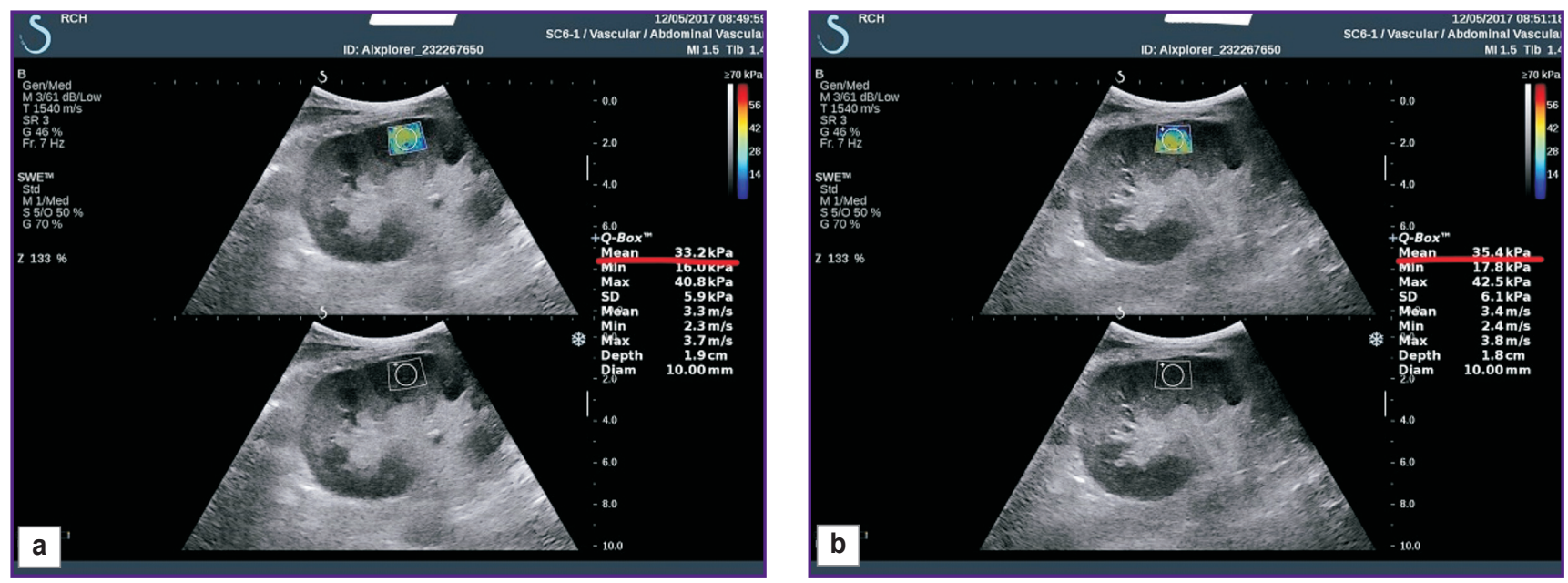

Figure 4. Shear wave ultrasound elastography of different areas of kidney transplant in Patient H. (group 2):

(a) parenchyma stiffness is $33.2 \mathrm{kPa}$ (top - the mode of shear wave ultrasound elastography, bottom - greyscale mode);

(b) parenchyma stiffness is $35.4 \mathrm{kPa}$ (top - the mode of shear wave ultrasound elastography, bottom - greyscale mode)

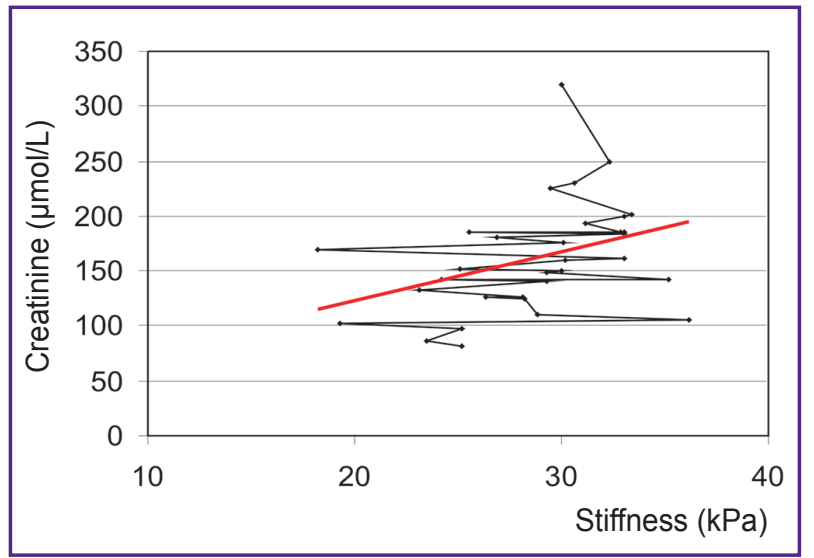

Figure 5. Correlation of creatinine level in blood serum and the values of parenchyma stiffness of kidney transplant in group $2(n=32$; $\mathrm{r}=0.375 ; \mathrm{p}=0.034$ ):

Thin black line - the graph built on the initial data; fat red line - linear fit (generalized) 
of kidney transplant in the mode of ultrasound Doppler sonography and SWUE in group 1. SWUE values are correlated with the clinical-laboratory values of kidney transplant.

Intraorganic hemodynamics in kidney transplants in case of transplantation occurring long ago with deviations in clinical laboratory values (increased creatinine level in blood serum) was characterized by reduced blood flow in interlobar and arcuate arteries, high RI, increased parenchyma stiffness. Figures 3 and 4 represent ultrasound investigations of kidney transplants with Doppler sonography and SWUE in patients from group 2. Correlations of creatinine level in blood serum and the parameters of parenchyma stiffness of kidney transplant in group 2 are shown in Figure 5.

The difference in parenchyma stiffness of kidney transplant in both groups was statistically significant $(p<0.05)$.

Thus, dynamic control over the state of intrarenal hemodynamics performed with color and spectral Doppler sonography and SWUE, along with clinical laboratory parameters, make it possible to detect dysfunction of kidney transplant at the initial stage of its manifestation. SWUE can be a supplementary diagnostic method of severity of kidney transplant fibrosis when transplantation was performed 1-3 years or more time before.

Conclusion. On the basis of the data of statistical processing of the results we identified diagnostic significance of shear wave ultrasound elastography for evaluation of the state of a transplanted kidney in short and long terms of follow-up.

An evident advantage of shear wave ultrasound elastography is its non-invasiveness, reliability of results, a possibility to obtain absolute values of stiffness of normal and pathologically changed tissue of kidney transplant which correlate with clinical laboratory values.
Financing of the Study and Conflict of Interests. The study was not financed by any sources; the authors declare no conflict of interests.

\section{References}

1. All-Russian public organization of transplantologists "Russian Transplant Society". Transplantatsiya pochki. Natsional'nye klinicheskie rekomendatsii [Kidney transplantation. National clinical recommendations]. Moscow: 2013.

2. Chow L., Sommer F.G., Huang J., Li K.C.P. Power Doppler imaging and resistance index measurement in the evaluation of acute renal transplant rejection. J Clin Ultrasound 2001; 29(9): 483-90, https://doi.org/10.1002/jcu.10010.

3. Osipov L.V. Technologies of elastography in ultrasound diagnostics. Review. Meditsinskiy alfavit. Diagnosticheskaya radiologiya i onkoterapiya 2013; 3-4(23): 5-21.

4. Tukhbatullin M.G., Galeeva Z.M., Bastrakova A.E. Ul'trazvukovaya elastografiya. Ekhografiya $v$ diagnostike zabolevaniy vnutrennikh i poverkhnostno raspolozhennykh organov [Ultrasonic elastography. Echography in the diagnosis of diseases of internal and superficial organs]. Kazan: Meditsinskaya kniga, 2016; p. 119-130.

5. Bastrakova A.E., Galeeva Z.M., Tukhbatullin M.G. Capabilities of complex echography in the early diagnosis of hepatic steatosis. Prakticheskaya meditsina 2016; 2(94): 48-50.

6. Zykin B.I., Postnova N.A., Medvedev M.E. Elastography: anatomy of the method. Promeneva diagnostyka, promeneva terapija 2012; 2-3: 107-113.

7. Zubarev A.R., Fedorova V.N., Demidova A.K., Rychkova I.V., Salomatina E.P., Kulchenko N.G. Ultrasonic elastography as a new step in differential diagnostics of thyroid nodules: literature review and provisional data. Meditsinskaya vizualizatsiya 2010; 1: 11-16.

8. Tukhbatullin M.G., Emel'kina L.A. Possibilities of complex ultrasonography in diagnostics of chronic hepatitis' activeness. Meditsinskaya vizualizatsiya 2007; 6: 97-101. 